\title{
Life-threatening bleeding from gastric dieulafoy's lesion in a pregnant woman with hellp syndrome: a case report and literature review
}

\author{
Chen $\mathrm{Si}^{i^{*}}$, Zhu Xiuli ${ }^{1}$, Xie $\mathrm{Li}^{1}$, Jia Yong ${ }^{1}$, Zhou Ying ${ }^{2}$ and Zhang Kaiguang ${ }^{1}$
}

\begin{abstract}
Background: Dieulafoy's lesion $(\mathrm{DL})$ is one of the rare causes of upper gastrointestional bleeding. This disease is characterized by small sub-mucosal arteriole that eroded the stomach mucosa and cause severe upper Gl bleeding without obvious ulceration. The most common location is fundus area of stomach and usually affects patients over 50 years of age with multiple comorbidities.

Case presentation: We report a case of life-threatening bleeding from DL during late pregnancy 31 weeks. Hemoclips were used twice through upper endoscopy with successful hemostasis. Unfortunately, she developed HELLP syndrome diagnosed 5 days after the Gl bleeding was stopped. Her pregnancy had to be terminated with delivery of a premature infant. She recovered from her illness and discharged from hospital uneventfully. There is no current report in literature of DL in pregnant woman subsequently suffered HELLP syndrome.
\end{abstract}

Conclusion: Endoscopic hemoclip application is an effective technique in the treatment of upper Gl bleeding from DL. For this patient, laparoscopic surgery or combination therapy before pregnancy may have been a suitable treatment on preventing rebleeding.

Keywords: Dieulafoy's lesion, Pregnancy, HELLP syndrome

\section{Background}

Dieulafoy's lesion (DL) is one of the rare, but potentially life-threatening causes of massive upper gastrointestinal (GI) bleeding. It accounts for about $1-2 \%$ of acute upper GI bleeding and occur more common in gastric fundic area at all age [1]. The diagnosis in pregnant women has not been reported. Due to the hemodynamic changes during pregnancy, DL is likely increase the morbidities and mortalities of pregnant women. Here we report a case that a pregnant woman who had massive upper GI hemorrhage from Dieulafoy's lesion of stomach. She was treated successfully with hemoclips endoscopically with supportive care including fluid resuscitation, blood transfusion. Unfortunately, the patient eventually

\footnotetext{
* Correspondence: css81729@163.com

${ }^{1}$ Department of Gastroenterology, Affiliated Provincial Hospital of Anhui Medical University, Hefei, China

Full list of author information is available at the end of the article
}

developed HELLP (hemolysis, elevated liver enzymes, and low platelets) syndrome. Termination of pregnancy prematurely to save the mother and baby's life was the only option.

In 1982, Weinstein firstly described the HELLP syndrome which including hemolysis, elevated liver enzymes and low platelets [2]. The incidence of this syndrome is only $0.2 \%-0.6 \%$ in pregnant women and the exact etiology has not been clearly defined. There were case reports about Dieulafoy's disease and HELLP syndrome occurred in women. To our knowledge, sequential occurrence of DL and HELLP syndrome were not reported so far.

\section{Case presentation}

A 27-year-old female patient was admitted to the gastroenterology department of our hospital due to hematemesis and melena. She was at 31 weeks and 


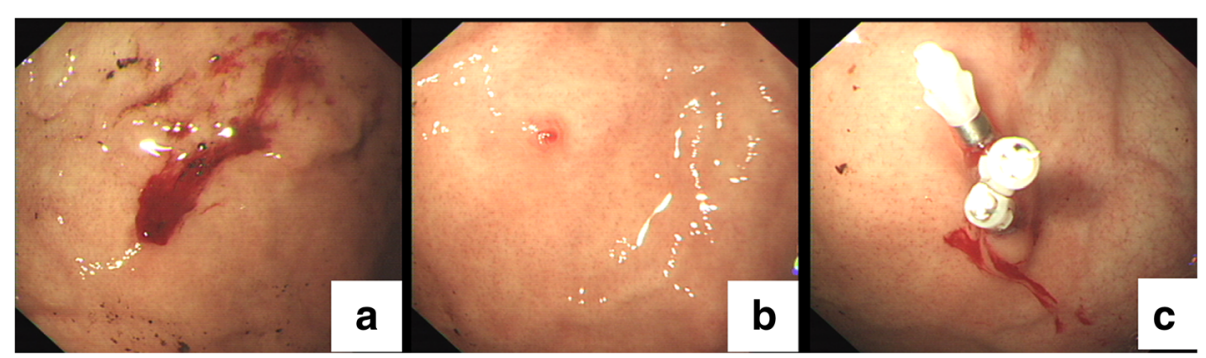

Fig. 1 a, b Gl endoscopy revealed active bleeding from gastric fundus and an exposed vessel protruded from a slight defect. c The lesion was treated with three hemoclips

4 days gestation. The patient had gastric DL diagnosed by esophagogastroduodenoscopy (EGD) 8 years ago when she presented with frequent hematemesis and black stools. EGD showed an blood vessel with bleeding over her gastric fundus about $6 \mathrm{~cm}$ from the gastroesophageal junction (Fig. 1). She had three episodes of upper GI bleeding from the same lesion without no overt symptoms.

In this case, emergency EGD (GIF Q260, Olympus Optical Co., Japan) revealed no active hemorrhage detected in upper digestive tract, other than the DL. The DL lesion in the fundus of stomach was treated with hemoclips for recurrent bleeding prophylaxis since she is having upper GI bleeding (Fig. 2). Unfortunately, massive hematemesis occurred again 2 days later and a second emergency gastroscopy was performed, which showed a spurting arterial bleeding without underlying ulceration close to the previous hemoclips. Hemoclips were applied again (Fig. 3). Finally, hemostasis based on endoscopic examination was achieved. However, even with blood transfusion support, the patient developed progressively anemia and thrombocytopenia without evidence of GI bleeding such as guaiac negative stools. Because of paroxysmal mild chest tightness and abdominal pains, Dexamethasone and magnesium sulfatate were administered intravenously to prevent eclampsia. Her laboratory examination showed: hemoglobin (HB), $62 \mathrm{~g} / \mathrm{L}$, platelet count, $19 \times 10^{9} / \mathrm{L}$, aspartate aminotransferase (AST) level and glutamic-pyruvic transaminase (ALT) were $136 \mathrm{IU} / \mathrm{L}$ and $252 \mathrm{IU} / \mathrm{L}$ respectively, serum total bilirubin, $55.7 \mu \mathrm{mol} / \mathrm{L}$, lactate dehydrogenase (LDH), $1740 \mathrm{IU} / \mathrm{L}$. Peripheral blood smear and elevated indirect bilirubin $(38.5 \mu \mathrm{mol} / \mathrm{L})$ revealed presence of schistocytes. Her blood pressure also increased to 155/ $91 \mathrm{mmHg}$. Meanwhile, there was signs of fetal distress and patient presented with acute abdominal pain. With evidence of acute hemolysis, thrombocytopenia and liver dysfunction, the pregnant woman was diagnosed with HELLP syndrome.

To prevent the further deterioration of mother and fatal condition, immediate delivery of the preterm baby by cesarean was recommended by hematology and gynecology consultation. She had uneventful surgery and discharged from hospital a week later. Her laboratory studies prior to discharge showed $\mathrm{HB}$ of $80 \mathrm{~g} / \mathrm{L}$ and platelet count of $88 \times 10^{9} / \mathrm{L}$. Serum bilirubin, AST and ALT were all within normal limits. No recurrence of GI bleeding was noted within 1-month of outpatient followup. Premature baby was also discharged from hospital after delivery within 30 days showing no complications.

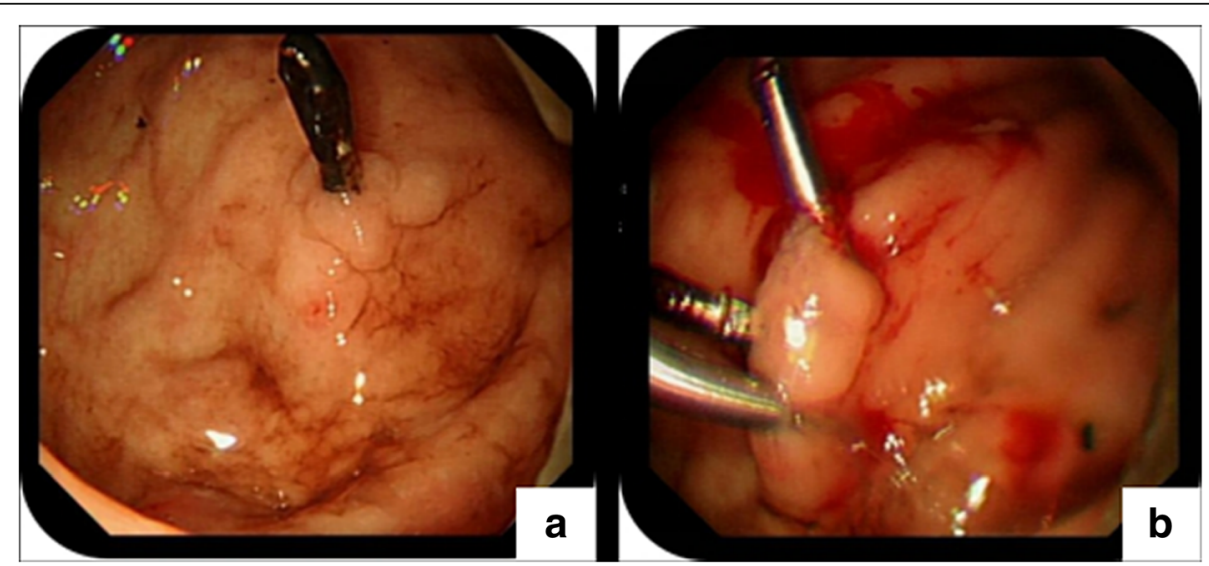

Fig. 2 a The possible bleeding site adjacent to old lesions and hemoclips last used can be observed. $\mathbf{b}$ The lesion was treated with titanium clamhemoclips for prevention of recurrent bleeding 


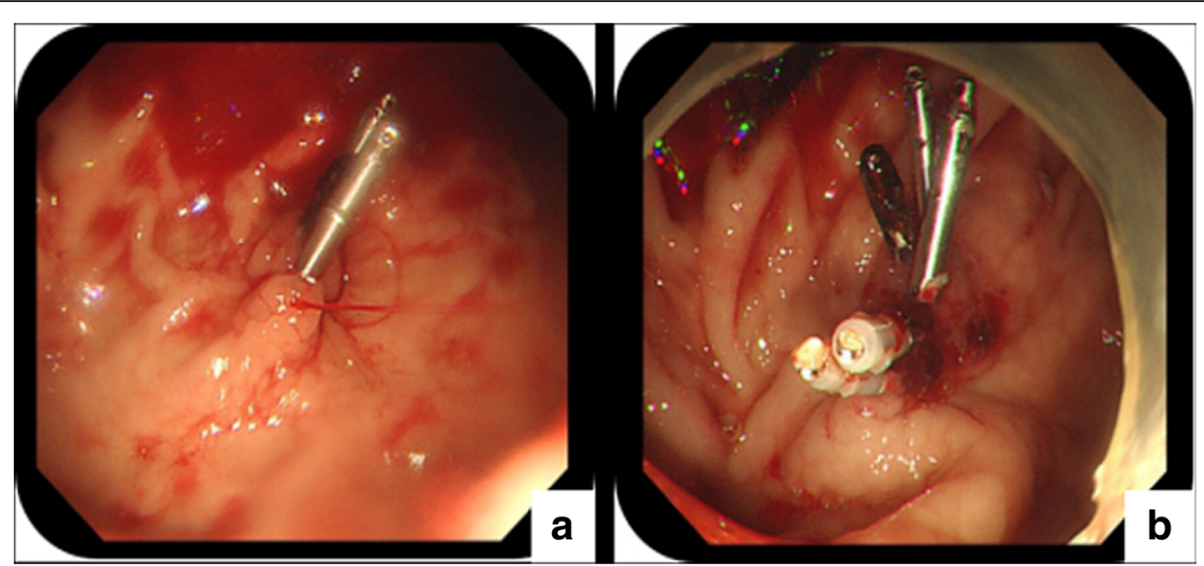

Fig. 3 a A pulsatile bleeding in the upper stomach without underlying ulceration. b Resolution of hemorrhage following placement of hemoclips

\section{Discussion and conclusion}

DL is one of the rare causes of GI bleeding. It accounts for about $1.5 \%$ of all GI hemorrhages [3, 4]. Due to the subtlety of the lesion, endoscopic visual criteria have been established for diagnosis of DL [5]. In this case we observed active arterial spurting from a small $(<3 \mathrm{~mm})$ defect in the gastric mucosa. DL associated upper GI bleeding during late pregnancy is extraordinarily rare in clinical practice. There was only one case report of duodenal DL associated bleeding in the first trimester of pregnancy in literature (Table 1) [6]. It can occur anywhere in the gastrointestinal tract. Some lesions are extragastric including duodenum and esophageal $[5,6]$.

Although there is no consensus on the best techniques to treat DL, GI endoscopy is a vital tool $[7,8]$. The common endoscopic treatment for DL associated GI bleeding include thermal probe, regional injection of epinephrine and mechanical methods [9-11]. The use of hemoclips proves to be easy and safe technique in treating DL GI bleeding and preventing rebleeding [11]. In our case, the pregnant woman suffered from pulsatile bleeding has been multiple hospitalizations for hemostasis which was controlled with emergency endoscopy two times. During late pregnancy, enlarged uterus can cause gastrointestinal compression leading to delayed gastric emptying. Retention of gastric juice and food may result in damage to the mucous membranes; thus, the risk of DL rebleeding may be higher in the third trimester.

Surgery is needed in about $3 \%$ to $16 \%$ of cases in patients with DL bleeding due to rebleeding after endoscopic therapies [12-14]. Laparoscopic surgery has been reported to treat patient with DL bleeding with advantages of minimally invasive intervention, but accurate localization of the bleeding site can be challenged [15]. For this patient rebleeding of DL occurred at the same site of stomach, so wide wedge resection of laparoscopic surgery with intraoperative endoscopy before pregnancy could have been a preferable treatment for patient with frequent recurrence of DL bleeding. Combined modality such as epinephrine injection and application of hemoclips therapy can achieve higher rate of initial hemostasis and lower rate of rebleeding when compared with monotherapy [12, 14]. It also may be a better option for our current case.

Even with the success of endoscopic therapy, massive hemorrhage has led to the progressive decline of PLT and eventually the HELLP syndrome occurred. It may be associated with massive hemorrhage and repeatedly erythrocyte transfusion. Moreover, hypoxia and heterologous related antigen during transfusion triggered immune reaction and inflammatory response that are both included in the etiology and pathogenesis of HELLP [16]. Damage to the vascular endothelial cell by activated platelets and other factors may cause thrombotic microangiopathy. This is considered to be the main pathogenetic mechanism of HELLP $[16,17]$.

The syndrome is typically observed in patients with severe preeclampsia. Although there was no severe preeclampsia in our case, laboratory results were consistent with the diagnosis of HELLP syndrome. The diagnostic criteria of the HELLP syndrome was initially proposed by Tennessee Classification System [18]. It includes

Table 1 Bleeding DL in pregnant woman: literature review

\begin{tabular}{llllll}
\hline Author & GA at diagnosis (weeks) & Treatment & Complications & Follow-up (months) & Outcome \\
\hline Benedetto et al. & 9 & Endoscopy with HCPs & no & 1 & Normal \\
Chen et al. & 31 & Endoscopy with HCPs & HELLP syndrome & 2 & Normal \\
\hline
\end{tabular}

GA gestational age, HCPs hemoclips 
presence of hemolysis, thrombocytopenia and hepatic changes with increased levels of enzymes. Pregnancy termination is still considered to be the best HELLP treatment method ensuring safety of the mother and infant $[17,18]$. Current case presents nonspecific symptoms and stable delivery of the fetus by cesarean section. The mother and infant recovered uneventfully following effective treatment.

The patient with DL followed by HELLP syndrome is rare. Koji et al. have reported a case of HELLP syndrome with pituitary apoplexy [19]. Endoscopic therapy, especially hemoclips, is an initial and main treatment of bleeding caused by DL. However, both combined endoscopic therapies and surgery might be needed in some patients who are in a high risk of life-threatening rebleeding. Pathogenesis of HELLP syndrome in patient with DL is unclear. Massive GI hemorrhage and inflammatory response may be the triggering factors that lead to HELLP syndrome.

\section{Abbreviations}

DL: Dieulafoy's lesion; GI: Gastrointestinal; HELLP: H (hemolysis) EL (elevated liver enzymes) LP (low platelet count); PLT: Platelet; EGD: Esophagogastroduodenoscopy

\section{Funding}

This report received no specific grant from any funding agency or institution.

\section{Availability of data and materials}

All data generated or analyzed during this study are included in this published article.

\section{Authors' contributions \\ $X L, J Y, Z X$ and $C S$ managed the patient; $X L$, ZK and CS worked on endoscopic therapy; $Z Y$ performed caesarian section; $C S$ and $Z X$ wrote the manuscript and $Z Y$ supervised it. All authors approved the final manuscript.}

\section{Ethics approval and consent to participate}

This article is a retrospective study and does not contain any studies with human subjects performed by any of the authors. So, the ethical approval was not necessary and Anhui Provincial Hospital medical ethics committee can offer exempt ethical statement in support.

\section{Consent for publication}

Written informed consent was obtained from the patient for publication of this case report and any accompanying images. A copy of the written consent is available for review by the Editor of this journal.

\section{Competing interests}

The authors declare that they have no competing interests.

\section{Publisher's Note}

Springer Nature remains neutral with regard to jurisdictional claims in published maps and institutional affiliations.

\section{Author details}

'Department of Gastroenterology, Affiliated Provincial Hospital of Anhui Medical University, Hefei, China. 'Department of Obstetrics, Affiliated Provincial Hospital of Anhui Medical University, Hefei, China.
Received: 24 January 2017 Accepted: 24 July 2017

Published online: 31 July 2017

\section{References}

1. Baxter M, Aly EH. Dieulafoy's lesion: current trends in diagnosis and management. Ann R Coll Surg Engl. 2010;92:548-54.

2. Benedetto C, Marozio L, Tancredi A. Biochemistry of HELLP syndrome. Adv Clin Chem. 2011;53:85-104

3. Chaer R, Helton WS. Dieulafoy's disease. Am Coll Surg. 2003;196:290-6.

4. Veldhuyzen van Zanten SJ, Bartelsman JF, Schipper ME, et al. Recurrent massive haematemesis from Dieulafoy vascular malformations-a review of 101 cases. Gut. 1986;27:213-22.

5. Malliaras GP, Carollo A, Bogen G. Esophageal Dieulafoy's lesion: an exceedingly rare cause of massive upper Gl bleeding. J Surg Case Rep. 2016;6:1-2.

6. Mangiavillano B, Luigiano C, Basile $\mathrm{S}$, et al. Is pregnancy a predisposing factor for Dieulafoy's duodenal lesion or only a coincidence? Clin Res Hepatol Gastroenterol. 2013;37(5):e119-20.

7. Nguyen DC, Jackson CS. The Dieulafoy's lesion: an update on evaluation, diagnosis, and management. J Clin Gastroenterol. 2015;49(7):541-9.

8. Alis $\mathrm{H}$, Oner $\mathrm{OZ}$, Kalayci MU, et al. Is endoscopic band ligation superior to injection therapy for Dieulafoy lesion? Surg Endosc. 2009;23(7):1465-9.

9. Schmulewitz N, Baillie J. Dieulafoy lesions: a review of 6 years of experience at a tertiary referral center. Am J Gastroenterol. 2001;96:1688-94.

10. lacopini F, Petruzziello L, Marchese M, et al. Haemostasis of Dieulafoy's lesion by argon plasma coagulation. Gastrointest Endosc. 2007:66:20-6.

11. Yamaguchi $Y$, Yamato $T$, Katsumi N, et al. Short-term and long-term benefits of endoscopic hemoclip application for Dieulafoy's lesion in the upper Gl tract. Gastrointest Endosc. 2003;57:653-6.

12. Eisenberg D, Bell R. Intraoperative endoscopy: a requisite tool for laparoscopic resection of unusual gastrointestinal lesions-a case series. J Surg Res. 2009;155:318-20.

13. Norton ID, Petersen BT, Sorbi $D$, et al. Management and long-term prognosis of Dieulafoy lesion. Gastrointest Endosc. 1999:50:762-7.

14. Chung IK, Kim EJ, Lee MS, et al. Bleeding Dieulafoy's lesions and the choice of endoscopic method: comparing the hemostatic efficacy of mechanical and injection methods. Gastrointest Endosc. 2000:52(6):721-4.

15. Alva S, Abir F, Tran D. Laparoscopic gastric wedge resection for Dieulafoy's disease following pre-operative endoscopic localisation with India ink and endoscopic clips. J Soc Laparoendosc Surg. 2006;10:244-6.

16. Abildgaard $U$, Heimdal K. Pathogenesis of the syndrome of hemolysis, elevated liver enzymes, and low platelet count (HELLP): a review. Eur J Obstet Gynecol Reprod Biol. 2013;166(2):117-23.

17. Dusse LM, Alpoim PN, Silv JT, et al. Revisiting HELLP syndrome. Clin Chim Acta. 2015;45 (Pt B):117-20.

18. Barton JR, Sibai BM. Diagnosis and management of hemolysis, elevated liver enzymes, and low platelets syndrome. Clin Perinatol. 2004;31:807-33.

19. Murao K, Imachi H, Muraoka T, et al. Hemolysis, elevated liver enzymes, and low platelet count (HELLP) syndrome with pituitary apoplexy. Fertil Steril. 2011:96(1):260-1.

Submit your next manuscript to BioMed Central and we will help you at every step:

- We accept pre-submission inquiries

- Our selector tool helps you to find the most relevant journal

- We provide round the clock customer support

- Convenient online submission

- Thorough peer review

- Inclusion in PubMed and all major indexing services

- Maximum visibility for your research 